\title{
LEADER EMOTIONAL INTELLIGENCE, TRANSFORMATIONAL LEADERSHIP, TRUST AND TEAM COMMITMENT: TESTING A MODEL WITHIN A TEAM CONTEXT
}

\author{
ANTON F SCHLECHTER \\ School of Management Studies \\ University of Cape Town \\ South Africa \\ JACOBA J STRAUSS \\ Department of Industrial Psychology \\ University of Stellenbosch \\ South Africa \\ Correspondence to: Anton Schlechter \\ e-mail: anton.schlechter@uct.ac.za
}

\begin{abstract}
This exploratory study tested a model within a team context consisting of transformationalleadership behaviour, team-leader emotional intelligence, trust (both in the team leader and in the team members) and team commitment. It was conducted within six manufacturing plants, with 25 teams participating. Of the 320 surveys distributed to these teams, 178 were received (which equals a $56 \%$ response rate). The surveys consisted of the multi-factor leadership questionnaire (MLQ), the Swinburne University emotional intelligence test (SUEIT), the organisational-commitment scale (OCS) (adapted for team commitment) and the workplace trust survey (WTS). The validity of these scales was established using exploratory factor analysis (EFA) and confirmatory factor analysis (CFA). The Cronbach alpha was used to assess the reliability of the scales. The model was tested using structural equation modelling (SEM); an acceptable level of model fit was found. Significant positive relationships were further found among all the constructs. Such an integrated model has not been tested in a team context before and the positive findings therefore add to existing teamwork literature. The finding that transformational leadership and leader emotional intelligence are positively related to team commitment and trust further emphasises the importance of effective leadership behaviour in team dynamics and performance.
\end{abstract}

Keywords: Transformational leadership, trust, team commitment, teamwork, teams

Organisations across the economic spectrum are making greater use of different types of teams and increasingly adopting teambased structures (Chuang, Church \& Zikic, 2004; Kratzer, Leenders \& Engelen, 2004; Natale, Sora \& Kavalipurapu, 2004). The pervasiveness of teams is evident in the various types of teams found in contemporary organisations. These include self-directed work teams, product-design teams, sales-account teams, cross-functional teams, process-redesign teams, strategic teams, management teams, project teams, coordination teams, think-tank teams, problem-solving teams, virtual teams, functional off-site teams, task teams and process-improvement teams (Duarte \& Snyder, 1999; Katzenbach \& Smith, 1994; Robbins, 2003; Woodcock \& Francis, 1994). Kreitner and Kinicki (2007) conclude that all teams can basically be divided into the following three categories: 1) teams that recommend things; 2) teams that make or do things; and 3) teams that run things.

The ever-increasing use of team-based structures within organisations is based on the belief that teamwork produces synergistic effects that are not achievable by individuals or even groups (Chuang et al., 2004; Kratzer et al., 2004; Natale et al., 2004). According to Katzenbach (1998, p. 36), "teams and good performance are inseparable, you cannot have one without the other". The synergistic effects obtained by teamwork benefit both organisations and individuals. Some of the benefits of teams to organisations, which have been well documented for some time now, include increased productivity, greater creativity, commitment and participation in a diversity of both large and small operations, improvements in quality, enhanced morale, more flexible responses to customer demands, reduced costs in supervision, innovation, leaner plant structures, substantial improvements in production cycle time and positive dynamic relationships among team members (Chuang et al., 2004; Harris, 1992; Katzenbach, 2000; Kratzer et al., 2004; Lewis, 1999; Natale et al., 2004; Parker \& Wall, 1998; Procter \& Mueller, 2000). On an individual level, teamwork has been found to promote learning, increase individual performance, enhance strategic understanding, establish proactive role orientations, increase job satisfaction and reduce strain experienced by employees (Harris, 1992; Procter \& Mueller, 2000).

Rabey (2003) and Erdem (2003) are of the opinion that organisations, in order to be globally competitive and responsive to the competitive challenges that they face, need to make greater use of team-based and teamwork structures to ensure their sustainability and success in an ever-changing world. Organisations have indeed realised that effective and empowered teams provide a way to accomplish organisational goals and meet the needs of a changing workforce (Procter \& Mueller, 2000).

Katzenbach (2000, p. 88) states that "a real team is never leaderless". Williams (1998) and Wilson, George and Wellins (1994) support this view, adding that, no matter how advanced a team becomes, there is still a need for leadership to enable the team to be optimally successful. In fact, "teams need more coaching, guidance, and attention in their early stages than the same individual contributors would need in a traditional structure" (Wilson et al., 1994, p. 6). Furthermore, without visionary leadership, teams can also easily lose their focus and sight of a company's strategic objectives (Procter \& Mueller, 2000). The role of a team leader therefore emerges as one of the 
most important aspects in establishing and sustaining effective teamwork and in ensuring that synergistic teamwork rewards are achieved (Lewis, 1999).

More than 20 years of research on the transformationalleadership construct has left little doubt that it can be likened to effective leadership and that it can encourage employees to perform beyond expectation (Yukl, 2002). Transformational leadership has been found to be related to a wide variety of positive individual and organisational outcomes (such as employee satisfaction, organisational commitment, satisfaction with supervision, extra effort, lower turnover intention and trust), including being empirically linked to increased organisational performance (Bass, 1985; Carlos \& Taborda, 2000; Yukl, 2002). Successful and effective leadership include, together with the usual (in other words, transactional) abilities of management, appropriate transformational abilities such as those proposed for transformational leadership (Bass \& Avolio, 1994)

Similarly, Goleman, Boyatzis and McKee (2002) and Prati, Douglas, Ferris, Ammeter and Buckley (2003) argue that emotional intelligence is a critical component of effective leadership, particularly for leaders who lead teams. Some emerging leadership theories imply that emotional and social intelligence is especially important for leaders and managers because cognitive and behavioural complexity and flexibility are important characteristics of competent leaders. In this document, the term leader emotional intelligence is used throughout to refer specifically to the emotional intelligence of a leader. This is to distinguish it from emotional intelligence in general.

Several authors stress the importance of effective relationships within teams (Biloslavo, 2004; Franken \& Braganza, 2006; Huusko, 2006; Law \& Chuah, 2004; Lewis, 1999, West, Tjosvold \& Smith, 2003). Many of the benefits associated with teamwork are dependent on good interpersonal relationships and are specifically influenced by the level of each individual team member's commitment to the team and trust in both the leader and her or his co-worker or team member (Bishop \& Scott, 1997; Bishop, Scott \& Casino, 1997; Katzenbach \& Smith, 1993).

On the one hand, team commitment has been found to be related to extra role behaviour (Becker \& Billings, 1993, Gregersen, 1993; Shore \& Wayne, 1993), job performance and satisfaction (Gallie \& White, 1993; Lawler, Mohrman \& Ledford, 1995; Mathieu \& Zajac, 1990), lower turnover, desired team and organisationalrelated outcomes (Becker \& Billings, 1993; Bishop et al., 1997; Mathieu \& Zajac, 1990) and team performance (Bishop \& Scott, 1997; Bishop et al., 1997; Scott \& Townsend, 1994). On the other hand, trust has been directly related to increased team performance, commitment, job satisfaction, organisational citizenship behaviours, organisational effectiveness and lower levels of intention to quit, sales levels and net profit (Cunningham \& MacGregor, 2000; Davies, Stankov \& Roberts, 1998; Dirks, 2000; Gomez \& Rosen, 2001; Konovsky \& Pugh, 1994; Mishra \& Morrisey, 1990; Morgan \& Hunt, 1994; Pillai, Schriesheim \& Williams, 1999; Rich, 1997; Tan \& Tan, 2000). There can be little argument that these two constructs are important for organisational success and performance and any endeavour to influence them positively should be pursued.

Leadership theory suggests that leadership behaviour has profound effects on subordinates, including how they relate both to the leader and to each other (Flood, Hannan, Smith, Turner, West \& Dawson, 2000; Knutson \& Miranda, 2000). Carlos and Taborda (2000) highlight that there cannot be trust among team members, team commitment and effective teamwork without effective leadership. This study was an attempt to investigate the potential impact of effective team-leadership behaviours on the two constructs - commitment and trust - mentioned in the previous paragraph. More specifically, the aim of this study was to investigate, within a teamwork context, the relationships among transformational-leadership behaviour, team-leader emotional intelligence, level of trust (both in the team leader and in team members) and team commitment. As far as could be established, these constructs have not been investigated together in an integrated fashion within a team context. It was therefore hoped that the findings of this study would provide new insights into the role that effective leadership can play in ensuring the conditions that are conducive for team effectiveness and performance.

\section{Transformational leadership and leader emotional intelligence}

Transformational leadership as proposed by Bass (1985) and Burns (1978) has received a great deal of attention, as it has delivered good results as a theory of effective leadership (Yukl, 2002). Steyrer (1998, pp. 807-808) describes transformational leadership as "the conveyance of values and meaning by means of exemplary action, as well as the articulation of an inspiring vision". Bass and Avolio (1995) identify behaviours that are characteristic of transformational leaders. Such leaders use inspirational motivation to be optimistic, enthusiastic and promote attainable goals for the future. Through individualised consideration, they show interest in the wellbeing of all subordinates. They are aware of all strengths and weaknesses among employees and allocate work accordingly. Transformational leaders appeal to and identify with subordinates on an emotional level and show that they are dedicated to their followers. They use intellectual stimulation to encourage subordinates constantly to re-examine their work and to revisit old problems. They encourage changes in thinking and listen to any idea, even if an idea may seem foolish at first (Yukl, 2002). Leaders who display transformational leadership behaviours have followers or subordinates who are motivated, committed, developed and rewarded to produce outstanding results that, in return, lead to organisational success and global competitiveness (Carlos \& Taborda, 2000). Similarly, within the team context, transformational leadership behaviour has been found to be positively related to satisfaction with leadership, effective decision making and overall team effectiveness (Bass, 1997; Carlos \& Taborda, 2000; Flood et al., 2000).

As leadership is concerned with social interactions between leaders and subordinates, emotional awareness and emotional regulation are important factors that affect the quality of these interactions and relationships (Wong \& Law, 2002). Mayer and Salovey (1997, p. 5), in a revision of their emotional-intelligence theory, define emotional intelligence as "the ability to perceive emotions, to access and generate emotions so as to assist thought, to understand emotions and knowledge, and to reflectively regulate emotions so as to promote emotional intellectual growth". They add that emotional intelligence refers to the ability to combine emotions and reasoning effectively, thus describing the extent to which people's cognitive capabilities are supported by emotions and the extent to which emotions are cognitively managed (Mayer \& Salovey, 1997). The revised version of the emotional-intelligence model places more emphasis on the cognitive components of emotional intelligence than the original conceptualisation of emotional intelligence by Goleman (1995) and Mayer and Salovey (1995). The revised model by Mayer and Salovey (1997) conceptualises emotional intelligence in terms of potential for intellectual and emotional growth and consists of the following four branches: 1) perception, appraisal and the expression of emotion; 2) the emotional facilitation of thinking; 3) the understanding, analysis and employment of emotional knowledge; and 4) the reflective regulation of emotions to further emotional and intellectual growth.

Goleman et al. (2002) argue that emotional intelligence is a critical component of leadership effectiveness, particularly as leaders deal with teams. Team leaders facilitate team- 
member interaction dynamics, build interpersonal trust and inspire team members to implement the strategic vision (Prati et al., 2003). Emotionally intelligent leaders evaluate team members' emotional situations in order to discourage detrimental interactions. By constructively resolving conflicts and establishing a relationship of cooperation and trust among members, they contribute to the collective motivation of team members (George, 2000).

Heise (1989) and Lewis (2000) indicate that if a team leader violates the established norm of emotional control, team members might perceive the leader as vulnerable, weak or ineffective. Goleman (1998) and Lewis (2000) both find that a leader's lack of emotional control is related to leader ineffectiveness.

Barling, Slater and Kelloway (2000), Prati et al. (2003) and Sosik and Megerian (1999) identify characteristics or behaviours of transformational leaders that overlap with behaviours of individuals considered to have high levels of emotional intelligence. Barling et al. (2000) propose that, consistent with the conceptualisation of idealised influence, leaders who are able to understand and manage their own emotions and display selfcontrol act as role models for their followers, enhancing their followers' trust and respect. Sosik and Megerain (1999) similarly suggest that the extent to which a leader demonstrates foresight, strong beliefs and consideration for the needs of others reflects her or his self-awareness and emotional intelligence. These are traits that are required for subordinates to rate their leaders as having idealised influence.

Barling et al. (2000) further suggest that leaders who are rated highly in the emotional-intelligence component of understanding emotions are more likely to perceive effectively the extent to which their followers' expectations can be raised; this is related to inspirational motivation. The ability to manage emotions and relationships permits the emotionally intelligent leader to understand her or his followers' needs and to react accordingly; this is related to individualised consideration. Emotionally intelligent leaders use charisma to influence team members in such a way that their beliefs are accepted without question and their followers invest emotionally in achieving the organisation's mission (Feyerherm \& Rice, 2002). Riggio and Pirozzolo (2002) conclude that the possession of emotional intelligence is both a core and a necessary component of the personal charisma demonstrated by leaders to enlist, direct and facilitate the dedication of individual effort and team performance

Emotionally intelligent individuals who are self-motivated feel more secure to face situations with confidence. Personal efficiency is also necessary to attract and motivate team members. Intellectual stimulation is a behaviour characteristic of both the transformational leader and the emotionally intelligent leader. Both are believed to be able to stimulate team members intellectually and to stimulate their professional development (Barling et al., 2000).

Finally, the emotionally intelligent leader allows a certain amount of individualised focus for each team member so that each feels important and necessary to the team.

The display of these behaviours by the team leader creates an atmosphere of empowerment in the team (Barling et al. 2000). Similarly, transformational leaders seek to empower their followers and enhance their desires for achievement and self-development, even so far as to develop themselves as transformational leaders in their own right (Bass \& Avolio, 1995).

On the basis of the arguments and findings described above, the following hypothesis was formulated:
$\mathrm{H}_{1}$ A positive relationship exists between transformational leadership and team-leader emotional intelligence.

\section{Leader emotional intelligence, trust and team commitment}

Rousseau, Sitkin, Burt and Camerer (1998, p. 395) define trust as "a psychological state comprising the intention to accept vulnerability based upon positive expectations of the intentions or behaviour of another". To trust therefore means to be vulnerable to the actions of another person and involves confidence in the intentions and actions of an individual group or institution and the expectation of ethical treatment (Carnevale \& Weschler, 1992). It should be noted that trust involves more than the formation of another's trustworthiness; it also involves a willingness to act, based on those judgements (Ferres \& Travaglione, 2003).

Organisational commitment is defined as the relative strength of an individual's identification with and involvement in a particular organisation (Robbins, 2003). Research distinguishes among the following three dimensions of organisational commitment: 1) affective commitment; 2) continuance commitment; and 3) normative commitment (Allen \& Meyer 1990). An employee's "profile of commitment" is the degree to which she or he is committed to the various focuses (such as a supervisor, team, department, function and organisation) that exist in the work environment (Becker \& Billings, 1993). Individuals experience various levels of commitment to each of these focuses (Becker \& Billings, 1993; Bishop \& Scott, 1996).

Team commitment can be defined in the same way as organisational commitment because teams, as in the case of organisations, develop goals and values that members may accept, members may choose to exert varying degrees of effort on the teams' behalf and members may have varying levels of desire to maintain their team membership (Becker \& Billings, 1993).

A distinction can be made between the commitment construct (in other words, the strength of involvement and identification) and its focus (such as commitment to the supervisor, team, department and/or organisation).

In this study, team commitment and organisational commitment are therefore believed to be similar in nature and to differ basically in terms of their focus (in other words, to whom or what a person is committed).

George (2000) lists four aspects of emotional intelligence that provide leaders with the ability to motivate and transform team members. These four aspects are as follows: 1) the ability to appraise others' emotions accurately as well as portray personal emotion effectively; 2) the ability to predict emotional reactions in various scenarios; 3 ) the ability to recognise that emotions are useful in the influence of behaviour; and 4) cognition of others and the ability to manage emotions. George (2000) and Lewis (2000) argue that the positive emotions of a team leader with a high level of emotional intelligence can elevate the team's emotional state and inspire members to invest themselves in the team and perform with more enthusiasm. This establishment of affective commitment has been shown to increase the motivation of team members (Ashforth \& Humphrey, 1995).

With the models developed by Salovey and Mayer (1990), Mayer and Salovey $(1997)$ and Goleman $(1995,1998)$ as a basis, Barling et al. (2000) propose that, consistent with the conceptualisation of idealised influence, leaders able to understand and manage their own emotions and to display self-control are role models for their followers. This enhances their followers' trust and respect for them. This ability to control emotions experienced at work is integral to effective leadership (Gardner \& Stough, 2002). The authors postulate that emotional intelligence provides a leader with the ability to maintain a positive 
appearance with subordinates, which instils feelings of security, trust and satisfaction and maintains an effective team. Prati et al. (2003) find that emotionally intelligent leaders facilitate team-member interactions better, which results in greater levels of interpersonal trust. Similarly, George (2000) finds that emotionally intelligent leaders, through constructively resolving conflicts, establish relationships characterised by cooperation and trust.

Abraham (1999) examined the role of job control as a moderator among emotional intelligence, job satisfaction and organisational commitment and suggests that healthy social relationships within an organisation increase employee loyalty and commitment. Furthermore, as emotional intelligence is related to the ability to interact with others, Abraham (1999) suggests that emotionally intelligent individuals might be more committed to their organisation. Abraham (1999) also finds that the social-skills component of emotional intelligence leads to stronger interpersonal relationships, which, in turn, influences organisational commitment. In an empirical study of this relationship, Humphreys, Brunsen and Davis (2005) find significant positive correlations among emotional intelligence, emotional coping ability and organisational commitment. Similarly, Gardner and Stough (2003) find a positive relationship between most aspects of emotional intelligence and organisational commitment.

On the basis of the arguments and findings described above, the following two hypotheses were formulated:

$\mathrm{H}_{2}$ A positive relationship exists between team-leader emotional intelligence and trust.

$H_{3}$ A positive relationship exists between team-leader emotional intelligence and team commitment.

\section{Transformational leadership, trust and team commitment}

Transformational leaders motivate their followers to perform beyond expectation by making them more aware of the importance and value of goals, inducing them to transcend selfinterest for the good of the group or organisation and appealing to their followers' higher-order needs (Bass, 1985). While theories of transformational leadership differ in some of the specific leadership behaviours that they identify, all theories posit trust as a central feature of the relationship that transformational leaders have with their followers. They postulate that it is due to the followers' trust in and respect for their leader that they are motivated to perform beyond expectation (Conger, Kanungo \& Menon, 2000; Podsakoff, MacKenzie, Moorman \& Fetter, 1990; Yukl, 2002). In a meta-analysis on trust and leadership, Dirks and Ferrin (2002) report findings that transformational leadership is strongly predictive of trust. Similarly, Pillai et al. (1999) find strong correlations between transformational leadership and trust. They also find structural-parameter estimates of the relationship between transformational leadership and trust to be 0,66 ( $p<0,01)$. MacKenzie et al. (2001) also report significant findings for this relationship.

Bishop and Scott (1996) suggest that it may be possible for leaders to influence an employee's team commitment by focusing on specific antecedent variables, such as task interdependence, inter-sender role conflict, resource-related role conflict, satisfaction with leadership and satisfaction with co-workers. Organisational as well as team-commitment research suggests that, in general, task interdependence (Mathieu \& Zajac, 1990), satisfaction with leadership (Brief \& Aldag, 1980; Nijhof, De Jong \& Beukhof, 1998) and satisfaction with co-workers (Brief \& Aldag, 1980) have positive influences on organisational and team commitment, while role-conflict variables influence this negatively (Bishop \& Scott, 1996).
Cheung (2000) points out that employees' level of commitment is influenced to the extent to which they believe that the organisation and the leader value their contribution and care about their well-being. Cheung (2000) implies that management or leaders can increase employees' commitment by providing them with a supportive climate that takes care of their well-being, that accepts their opinion, that provides them with encouragement, adequate information and good working conditions and that formulates clear and reasonable goals. Isaksen and Lauer (2002) apply a collaborative climate to teamwork and find that a team climate supports cooperation and collaboration within the team. Isaksen and Lauer (2002) further find that a climate of fairness in teams causes team members to believe that their own interests and those of the team coincide. Colquitt (2002) finds similar results with the measurement of a procedural-justice climate within teams. Characteristics of such teams are superior performance and low absenteeism.

DeCottiis and Summers (1987) cite various instances of climate dimensions such as trust, cohesiveness and autonomy being associated with organisational commitment. Their results indicate that climate explains $43 \%$ of variance in organisational commitment. Roodt (1997) argues that the use of climate as a predictor could enhance organisational-commitment predictor models. His findings - that climate dimensions such as identity, rewards and standards explain $56 \%$ of variance in organisational commitment - support those of DeCottiis and Summers (1987). Pillai et al. (1999) establish and test the integrated model based on the relationships among transformational leadership, organisational justice, trust and commitment.

On the basis of the arguments and findings described above, the following two hypotheses were formulated:

$H_{4}$ A positive relationship exists between transformational leadership and trust.

$H_{5}$ A positive relationship exists between transformational leadership and team commitment.

\section{Trust and team commitment}

The central importance of interpersonal trust for sustaining individual, team and organisational effectiveness is increasingly being recognised (Dirks \& Ferrin, 2002). Team transactions characterised by interpersonal trust promote an environment in which individuals feel free to express their ideas, engage in problem solving and resolve differences of opinion (TschannenMoran, 2001). Trust in teams and teamwork is effected by levels of interpersonal trust, which is, in turn, linked to social and leadership relationships, organisational effectiveness, organisational climate and health, and performance and achievement (Tschannen-Moran, 2001). Work relationships characterised by trust may strengthen cooperation, reduce conflict, increase organisational commitment and diminish the tendency to leave (Morgan \& Hunt, 1994; Tschannen-Moran, 2001). When team members do not trust each other, however, they are not likely to collaborate. Mutual trust within teams affects the level of confidence that team members show in interpersonal relations and work performed on the collective level (Larson \& La Fasto, 1989). Team leaders in team-based organisations, mindful of the dynamics of trust, take the risks necessary to develop and strengthen collective trust, which leads to greater team commitment and enables more effective teamwork (Katzenbach \& Smith, 1993).

On the basis of the arguments and findings described above, the following hypothesis was formulated:

$H_{6}$ A positive relationship exists between trust and team commitment. 


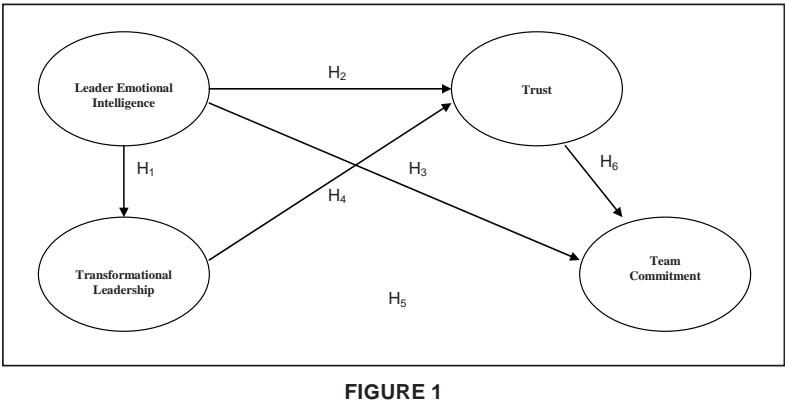

The Integrated Conceptual Model

\section{Proposed integrated conceptual model}

The discussion presented above used various arguments and findings from previous studies to establish theoretical bivariate relationships among the constructs under investigation. These bivariate relationships were then combined in such a manner as to produce an integrated conceptual model. The model is graphically presented in Figure 1. This study was an attempt to validate the model.

\section{RESEARCH DESIGN}

\section{Research approach}

A cross-sectional quantitative approach was followed. Primary data were collected by means of standardised instruments in a non-random field survey. The collected data were analysed to explain observations on an ex post facto basis.

\section{Participants}

The research was conducted in six manufacturing plants within South Africa. Two of the plants are located in the Western Cape, two in the Free State and two in KwaZulu-Natal. These plants were selected because they have implemented mission-directed work teams. Such teams are an organisation-wide organisational development (OD) intervention that aims to achieve high and continuously improving levels of quality, speed, cost and morale through the use of team-based structures and processes.

A total of 25 teams from the six plants was selected to take part in the survey and 320 questionnaires were distributed to the members of these teams. A total of 178 completed responses was received: 60 (34\%) from Branch One, 42 (23\%) from Branch Two 19 (11\%) from Branch Three, 23 (13\%) from Branch Four, 24 (13\%) from Branch Five and $10(5,6 \%)$ from Branch Six. The average age of the respondents was $36,66(\underline{\mathrm{SD}}=9,63)$. The respondents had an average of $8,82(\underline{\mathrm{SD}}=7,72)$ years' service to their companies and had been reporting to their current supervisors or line manager for an average of $3,44(\underline{\mathrm{SD}}=3,25)$ years.

Table 1 summarises further aspects of the sample demographics.

The respondents represented the following occupations in the following numbers: 55 administrative employees, 74 shop-floor workers, 33 supervisors and 16 heads of department. The sample was believed to be fairly representative of the demographic profile of the organisations. From Table 1, it is apparent that the sample consisted of considerably more males than females ( $75 \%$ versus $25 \%$, respectively). As this study was conducted in manufacturing plants and the majority of participants were shop-floor workers, it could be expected that there would be more males in the population (and therefore sample). The same explanation could further be responsible for the relatively low level of education. From Table 1, it can be seen that the race distribution in the obtained sample was relatively even over the different racial groups. Considering the length of time that the respondents had been working in the organisations and for their supervisors, it would therefore be fair to presume that the respondents knew their organisations and supervisors well enough to answer the research questions.

\section{Measuring instruments}

The survey that was completed by the respondents consisted of five sections. Four sections consisted of existing questionnaires that measured the constructs under investigation. These are discussed below. Biographical questions made up the fifth section.

\section{Transformational leadership}

Transformational leadership was measured by using the multifactor leadership questionnaire (MLQ), developed by Bass and Avolio (1995). The 20 items of the MLQ relevant to the transformational-leadership subscale were used for this study. This scale consists of the following items: idealised influence (eight items), inspirational leadership (four items), intellectual stimulation (four items) and individualised consideration (four items). In previous studies, the internal consistency for the transformational leadership subscale was found to be satisfactory. Hartog \& Van Muijen (1997) report satisfactory (i.e. $>0,70$ ) Cronbach alphas of 0,93 for idealised influence, 0,72 for inspirational motivation, 0,81 for intellectual stimulation and 0,75 for individualised consideration. Lowe, Kroeck and Sivasubramaniam (1996) also report satisfactory Cronbachalpha coefficients of 0,92 for charisma, 0,86 for intellectual stimulation and 0,88 for individualised consideration.

\section{Emotional intelligence}

Emotional intelligence was measured by using the Swinburne University emotional intelligence test (SUEIT), which indexes the way that people typically think, feel and perform with emotions at work. During the development of the SUIET, a factor analytic study with a representative sample of the general population was done in Australia $(\underline{N}=310)$. Six of the predominant measures of emotional intelligence were included in this battery. These were as follows: 1) the Mayer, Salovey, Caruso EI test (MSCEIT); 2) the bar-on emotional-quotient inventory; 3) the trait meta-mood scale; 4) the 20-item Toronto Alexithymia scale-II (TAS-20); 5) the Schutte scale; and 6) the Tett scale (Palmer \& Stough, 2002).

The first step was to factor-analyse each of these six scales separately. The component-score coefficients were then used to form factor-based scores for each of the dimensions identified

TABLE

Respondents' biographical details

\begin{tabular}{lrl}
\hline BIOGRAPHICAL VARIABLE & N & PERCENTAGE \\
\hline Gender & & \\
\hline Male & 133 & $74.7 \%$ \\
Female & 45 & $35.3 \%$ \\
Total & 178 & $100 \%$ \\
Race & & \\
\hline Asian & 19 & $10.7 \%$ \\
Black & 49 & $27.5 \%$ \\
Coloured & 58 & $32.6 \%$ \\
White & 52 & $29.2 \%$ \\
Total & 178 & $100 \%$ \\
Educational level & & \\
\hline 7 or less years & & \\
Grade 8-10 & 3 & $1.7 \%$ \\
Grade 12 & 52 & $29.2 \%$ \\
Certificate or diploma & 79 & $44.4 \%$ \\
First degree & 42 & $23.6 \%$ \\
Total & 2 & $1.1 \%$ \\
& 178 & $100 \%$ \\
\hline
\end{tabular}


for each test. These dimensions were again used as "items" for the principal-component analysis. This resulted in five factors having eigenvalues greater than one, a result that matched the scree criterion and accounted for $58 \%$ of the total variance (Palmer \& Stough, 2002). The five factors that were identified were as follows: 1) emotional recognition and expression; 2) the understanding of emotions; 3 ) emotions direct cognition; 4) emotional management; and 5) emotional control.

This empirically-based model of emotional intelligence, consisting of 64 items, is unidimensional, which means that the factors represent a set of related abilities concerned with how effectively emotions are dealt with in the workplace (Palmer \& Stough, 2002)

The $360^{\circ}$ version of the SUIET was used in this study. Participants were requested to indicate, on a six-point Likerttype scale, the extent to which the 64 statements were true of the way that their team leaders or supervisors typically thought, felt and dealt with emotions at work. In previous studies, the overall scale reliability (the standardised Cronbach alpha) of the questionnaire was found to be 0,88 , while the Cronbach alphas for the subscales were found to be as follows: 1) 0,73 for emotional recognition and expression; 2) 0,83 for the understanding of emotions external; 3) 0,63 for emotions direct cognition; 4) 0,72 for emotional management; and 5) 0,72 for emotional control. The full-scale reliability and most subscales were high, with the exception of the emotions direct cognition subscale (Palmer \& Stough, 2002).

\section{Team commitment}

Allen and Meyer (1990) originally developed the organisational commitment scale (OCS) in an attempt to reconcile the various conceptualisations of organisational commitment. The OCS reflects a three-dimensional approach to commitment. It measures the following: 1) affective commitment; 2) continuance commitment; and 3) normative commitment. The final version of the questionnaire consists of 24 items (in other words, eight items per dimension). Bennett and Boshoff (personal communication, 5 November 2003) adapted these 24 items of the OCS by changing the referent subject of the items from "the organisation" to "the team". They further developed an additional eleven items for the scale to measure the same three dimensions conceptualised by Allen and Meyer (1990).

The Bennett and Boshoff-adapted team-commitment scale was completed by 600 middle managers from 50 organisations. The overall scale reliability (in other words, the standardised Cronbach alpha) of the questionnaire was found to be 0,89 , while the Cronbach-alpha coefficients for the subscales were found to be as follows: 1) 0,98 for affective commitment; 2) 0,87 for continuous commitment; and 3) 0,87 for normative commitment (Bennett and Boshoff, personal communication, 5 November 2003).

\section{Trust}

Trust was measured by means of the workplace trust survey (WTS), which was developed and validated by Ferres and Travaglione (2003). This 36-item instrument is based on a conceptualisation of trust that consists of three dimensions. It was constructed to assess trust at the following three levels: 1) trust in the organisation; 2) trust in co-workers; and 3) trust in the leader (or supervisor or line manager). For the purposes of this study, only the two last-mentioned subscales were used.

Support was obtained for the internal reliability, construct validity, partial known-instrument validity and divergent/ convergent validity of the three emergent WTS factors (Ferres \& Travaglione, 2003). The WTS was subjected to further psychometric evaluation through recent research in Australia and South Africa (Ferres, Connell \& Travaglione,
2004). In these studies, the Cronbach-alpha coefficients ranged between 0,90 and 0,97 (trust in the organisation $=0,97$; trust in co-workers $=0,94$; and trust in supervisors $=0,90$ ) and were thus found to be satisfactory. In the standardisation sample, these three factors explained $59,5 \%$ of the variance in the data (Van Wyk, personal communication, September 2002).

\section{Procedure}

Respondents received a hard copy of the composite questionnaire and a covering letter. The human-resources manager visited the sites and was personally present while the respondents received, completed and returned the questionnaires. This was done during working hours. Complete confidentiality and anonymity could be guaranteed, as there were no identifiers on the questionnaires. The respondents were requested to evaluate their team leaders' transformational-leadership behaviours and emotional intelligence and their own levels of trust and team commitment.

\section{Statistical analysis of the data}

The dimensionality and factorial/configurational validity of each instrument were first assessed. This was done by subjecting each of the measurement scales first to exploratory factor analysis (EFA) and then to confirmatory factor analysis (CFA) to assess construct validity. EFA was conducted using SPSS Version 14 and CFA was conducted using Lisrel version 8,53 .

The data collected with each measurement scale were first subjected to EFA to identify a minimal set of factors that accounted for a major portion of the total variance of the original items. EFA was conducted by means of the principal-axis factoring-extraction method utilising a direct Oblimin rotation. This choice of extraction method and rotation accords with the recommendations of Fabrigar, Wegener, MacCallum and Strahan (1999) and Gorsuch (1997). The scree plot and the Kaiser criterion, which specifies that only factors with eigenvalues of 1,00 or greater should be retained, were further used as a guide to determine the appropriate number of factors. The factor loadings were then inspected. An item was rejected if it had a loading of $\leq 0,30$ on a factor or when it was considered to have cross-loaded, in other words if the item loadings differed by $\leq 0,25$ across-factors. EFA was then repeated and all items that did not comply with the above inclusion criteria were rejected until a "clean" factor structure was obtained. Next, both the final-factor structures of the measurement models as obtained from EFA and the original measurement model proposed by the author/s were imposed on the data using a CFA. The maximum-likelihood (ML) method was used to estimate all the models.

Structural equation modelling (SEM) was used to analyse the proposed model to get an idea of how consistent the data were with the complete hypothesised model. Lisrel version 8,53 was utilised for this analysis. A structural model including all the constructs and their underlying dimensions was drawn up and tested with this statistical technique. The ML method was used to estimate all the models.

\section{RESULTS}

\section{Results from EFA}

\section{Transformational leadership}

The first round of EFA was performed on the 178 responses to the 20 items of transformational leadership. After inspection of the scree plot and eigenvalues, it was decided that a single factor existed. All the items conformed to the selection criteria, which means that no items were rejected. For the final factor structure, the eigenvalue of 10,34 and $51,70 \%$ of the variance 
TABLE 2

Goodness of fit statistics for the various measurement models

\begin{tabular}{|c|c|c|c|c|c|c|c|}
\hline & SUEIT & & MLQ & & COMMITMENT & & TRUST \\
\hline & $\begin{array}{l}\text { Original } \\
\text { measurement } \\
\text { model }\end{array}$ & $\begin{array}{l}\text { EFA derived } \\
\text { measurement } \\
\text { model }\end{array}$ & $\begin{array}{l}\text { Original } \\
\text { measurement } \\
\text { model }\end{array}$ & $\begin{array}{l}\text { EFA derived } \\
\text { measurement } \\
\text { model }\end{array}$ & $\begin{array}{l}\text { Original } \\
\text { measurement } \\
\text { model }\end{array}$ & $\begin{array}{l}\text { EFA derived } \\
\text { measurement } \\
\text { model }\end{array}$ & $\begin{array}{l}\text { Original and EFA } \\
\text { derived model }\end{array}$ \\
\hline Degrees of Freedom & 1942 & 1538 & 164 & 170 & 557 & 296 & 250 \\
\hline Minimum Fit Function Chi-Square & $\begin{array}{l}4386.1748 \\
(P=0.0)\end{array}$ & $\begin{array}{l}2885.9232 \\
(P=0.0)\end{array}$ & $\begin{array}{l}453.1657 \\
(P=0.0)\end{array}$ & $\begin{array}{l}418.2594 \\
(P=0.0)\end{array}$ & $\begin{array}{l}1510.2643 \\
(P=0.0)\end{array}$ & $\begin{array}{l}674.9817 \\
(P=0.0)\end{array}$ & 700.8118 \\
\hline$x^{2} / \mathrm{df}$ ratio & 2.26 & 1.88 & 2.76 & 2.46 & 2.71 & 2.28 & \\
\hline $\begin{array}{l}\text { Root Mean Square Error of } \\
\text { Approximation (RMSEA) }\end{array}$ & 0.09290 & 0.06488 & 0.09556 & 0.09149 & 0.1152 & 0.08886 & 0.1125 \\
\hline Normed Fit Index (NFI) & 0.6640 & 0.7301 & 0.9505 & 0.9494 & 0.8227 & 0.8455 & 0.9004 \\
\hline Non-Normed Fit Index (NNFI) & 0.7701 & 0.8462 & 0.9626 & 0.9656 & 0.8715 & 0.8971 & 0.9263 \\
\hline Comparative Fit Index (CFI) & 0.7786 & 0.8518 & 0.9677 & 0.9693 & 0.8797 & 0.9063 & 0.9333 \\
\hline Incremental Fit Index (IFI) & 0.7800 & 0.8527 & 0.9678 & 0.9693 & 0.8802 & 0.9070 & 0.9335 \\
\hline Relative Fit Index (RFI) & 0.6512 & 0.7199 & 0.9426 & 0.9434 & 0.8106 & 0.8304 & 0.8900 \\
\hline $\begin{array}{l}\text { Standardised Root Mean Square } \\
\text { Residual (RMR) }\end{array}$ & 0.1306 & 0.089 & 0.054 & 0.054 & 0.1242 & 0.1041 & 0.2401 \\
\hline Goodness of Fit Index (GFI) & 0.5357 & 0.6527 & 0.8108 & 0.8075 & 0.6240 & 0.7643 & 0.7240 \\
\hline Adjusted Goodness of Fit Index (AGFI) & 0.5028 & 0.6267 & 0.7577 & 0.7622 & 0.5748 & 0.7205 & 0.6688 \\
\hline
\end{tabular}

were explained. The Cronbach-alpha coefficient for the instrument was found to be 0,95 and was therefore considered to be satisfactory (i.e. $>0,70$ ).

\section{Emotional intelligence}

The first round of EFA was performed on the responses to the 64 items of the SUIET. After inspection of the scree plot and eigenvalues, it was decided that a two-factor solution would be most appropriate. During the first round, five items were rejected, as they did not comply with the inclusion criteria. The next round led to the rejection of one item. This resulted in the obtaining of the final "clean" factor structure, which contained the remaining 58 items.

EFA yielded two factors with eigenvalues exceeding 1: factor one had an eigenvalue of 9,75 , which explains $16,81 \%$ of the total variance; and factor two had an eigenvalue of 6,54 , which explains $11,29 \%$ of the total variance. The two factors together explained $28,10 \%$ of the total variance. The Cronbach alpha coefficient for the instrument in this study was 0,75 and, for the factors, was as follows: 0,72 for factor one; and 0,82 for factor two. After inspecting the items that loaded meaningfully on the two factors, they were identified as follows: factor one $=$ understanding and displaying emotions; factor two = perception and control over emotions.

\section{Team commitment}

The first round of EFA was performed on the 178 responses to the 35 items of the team-commitment questionnaire. After inspection of the scree plot and eigenvalues, it was decided that a three-factor solution would be most appropriate. The final factor structure was obtained after three rounds of EFA (in round one, five items were excluded, in round two, two items were excluded and, in round three, another two items were excluded). The final factor structure contained 26 items.

EFA yielded three factors with eigenvalues exceeding 1: factor one had an eigenvalue of 6,45 , which explains $24,79 \%$ of the total variance; factor two had an eigenvalue of 4,51 , which explains $17,36 \%$ of the total variance; and factor three had an eigenvalue of 1,86 , which explains $7,17 \%$ of the total variance. The three factors together explained $49,32 \%$ of the total variance. The Cronbach alpha coefficient for the instrument in this study was 0,85 and, for the factors, was as follows: 0,85 for factor one; 0,80 for factor two; and 0,80 for factor three. After inspecting the items that loaded meaningfully on the three factors, they were identified as follows: factor one = affective commitment; factor two = continuance commitment; and factor three = normative commitment.
Trust

After inspection of the scree plot and eigenvalues, it was decided that a two-factor solution would be most appropriate. During the first round of EFA on the 178 responses to the items of the two subscales (in other words, trust in the leader and trust in the co-worker), all the items were found to conform with the selection criteria and no items were therefore rejected.

EFA yielded two factors with eigenvalues exceeding 1: factor one had an eigenvalue of 9,47 , which explains $39,45 \%$ of the total variance; and factor two had an eigenvalue of 1,89 , which explains $7,86 \%$ of the total variance. The two factors together explained $47,31 \%$ of the total variance. The Cronbach alpha coefficient for the instrument in this study was 0,95 and, for the factors, was as follows: 0,94 for factor one; and 0,94 for factor two. The items loaded on the same dimensions as the original scale. Factor one was therefore labelled trust in the supervisor and factor two was labelled trust in co-workers.

\section{CFA of measurement instruments}

The fit indices obtained from the CFA of both the EFA-derived measurements models and the original measurement models as proposed by the author, when imposed on the data, are summarised in Table 2.

When the fit indices summarised in Table 2 are considered, it would seem that none of the instruments do, in fact, fit the data very well. The indices in practically all cases lie just outside what is accepted as good fit when compared to "rule of thumb" (Bollen \& Long, 1993; Diamantopoulos \& Siguaw, 2000; Kelloway, 1998). From Table 2, however, it is evident that, when the fit indices obtained from the EFA-derived measurement models are numerically compared with the indices obtained from the original measurement models and when "rule of thumb" is taken into account, it would seem that the indices were found to favour the EFA-derived measurement models over the original measurement models. In the case of the trust questionnaire, there was, of course, no difference, as the EFAderived measurement models did not differ from the original. Based on the results described above, it was therefore decided that the EFA-derived measurement models would be more appropriate to use as the measures of the constructs in this study and that they have demonstrated adequate construct validity and reliability.

\section{Structural model}

As the MLQ was found to be unidimensional, items were randomly broken up into four "parcels" and were used as indicators of the latent variables in the model. The conceptual model, as depicted in Figure 1, was used to design the structural 


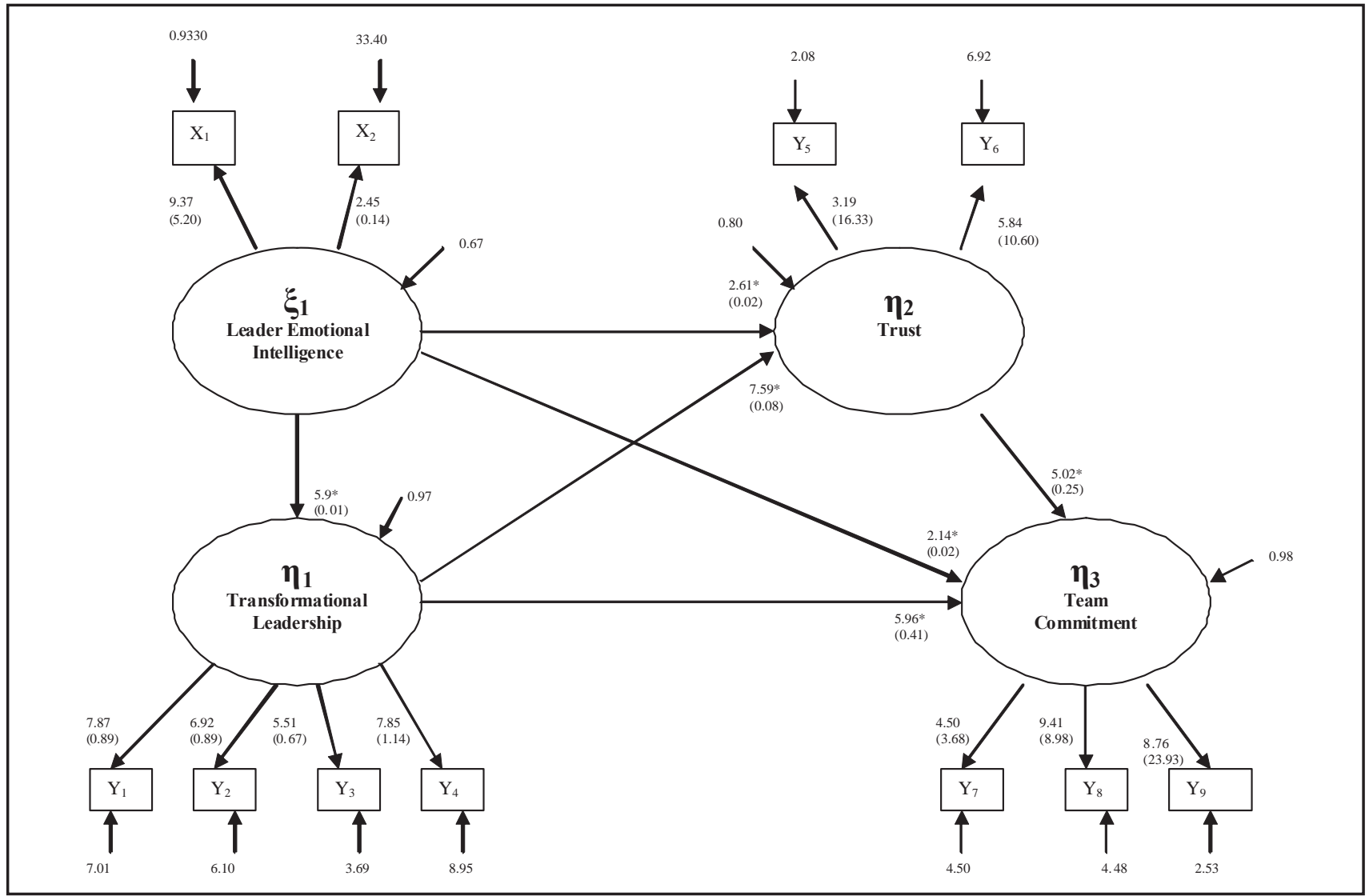

Manifest Variables/Indicators:

$\mathrm{X}_{1}=$ Understanding and displaying emotions, $\mathrm{X}_{2}=$ Perception and control over emotions, $\mathrm{Y}_{1}=\mathrm{TFL} 1, \mathrm{Y}_{2}=\mathrm{TFL} 2, \mathrm{Y}_{3}=$ TFL3, $\mathrm{Y}_{4}=$ TFL4, $\mathrm{Y}_{5}=$ Trust in the team leader, $\mathrm{Y}_{6}=$ Trust in the co-workers, $Y_{7}=$ Affective Commitment, $Y_{s}=$ Continuance Commitment, $Y_{9}=$ Normative Commitment

FIGURE 2

Structural Model with Maximum Likelihood Parameter Estimates for Leader EI, Transformational Leadership, Trust and Team Commitment

model. After the Lisrel syntax was submitted, the structural model converged.

The significant minimum fit chi-square statistic $(=103,0251$ and $\mathrm{p}=0,0000)$ obtained demonstrated imperfect model fit and implied that the model might not be adequate and might therefore have to be rejected. The chi-square statistic is sensitive to multivariate normality and sample size (Diamantopoulos \& Siguaw, 2000). To counter this problem, Bollen and Long (1993) and Kelloway (1998) recommend that the ratio of chi square and degrees of freedom $\left(\chi^{2} / \mathrm{df}\right)$ be used instead. A value of between 2 and 5 is believed to indicate good fit (Bollen \& Long, 1993; Kelloway, 1998); a value of 2,7 was obtained for the structural model. When evaluated against this standard, it therefore seemed that the model did fit the data adequately. Root mean square error of approximation (RMSEA) is based on the analysis of residuals, with smaller values indicating a better fit with data. Diamantopoulos \& Siguaw (2000) contend that a value lower than 0,08 indicates acceptable fit. The model achieved an RMSEA value of 0,0683 , which falls within what is regarded as acceptable fit. It was therefore believed that the structural model, based on these two indices, had achieved adequate fit.

The structural model, with its ML parameter estimates, is presented in Figure 2. The t-statistics for each of the structural coefficients were examined to determine whether they differed significantly from zero.

The gamma $(\Gamma)$ and beta $(B)$ matrices illustrating the direct effects between the constructs are depicted in Tables 3 and 4 , respectively. The $t$-values are presented in brackets. " $t \geq 1,96$ " implies a significant parameter estimate $(p<0,05)$ (Diamantopoulos \& Siguaw, 2000).
From the t-values reported in Table 3, it is evident that positive significant relationships $(t>1,96)$ exist among leader emotional intelligence and transformational leadership $(t=5,9)$, trust $(t=2,6)$ and team commitment $(t=2,1)$. These relationships were significant at $\mathrm{p}<0,05$. The results led to the acceptance of the first three hypotheses (in other words, $\mathrm{H}_{1}, \mathrm{H}_{2}$ and $\mathrm{H}_{3}$ ).

The beta (B) matrix is reported in Table 4. It can be argued from this matrix that significant positive relationships $(t>1,96)$ exist among transformational leadership and trust $(t=7,6)$, trust and team commitment $(t=5,0)$ and transformational leadership and team commitment $(t=6,0)$. The results led to the acceptance of $\mathrm{H}_{4}, \mathrm{H}_{6}$ and $\mathrm{H}_{5}$.

\section{DISCUSSION}

Given the potentially advantageous performance implications of teamwork (Chuang et al., 2004; Erdem, 2003; Kratzer et al., 2004; Natale et al., 2004; Rabey, 2003), it is important to gain an understanding of the constructs that underlie effective teams. This study therefore investigated the relationships among transformational leadership, leader emotional intelligence, trust, and team commitment. The latter two constructs are known to be present within effective teams and are related to various desirable outcomes. The objective of the study was to conduct an empirical test on a conceptual model consisting of the four constructs. Before the model could be empirically investigated, however, the construct validity and internal reliability of the measures of the constructs had to be assessed.

EFA provided support for both dimensions of the trust scale (Ferres et al., 2004) as well as for the three dimensions of the 
Table 3

Gamma matrix of the structural model

\begin{tabular}{lr}
\hline $\mathbf{N}=\mathbf{1 7 8}$ & LEADER EI \\
\hline Trust & 0.0184 \\
& $(0.007)$ \\
Transformational leadership & $2.606^{*}$ \\
& 0.0590 \\
Team Commitment & $(0.0010)$ \\
& $5.900^{*}$ \\
& 0.0338 \\
& $(0.01579)$ \\
& $2.141^{*}$ \\
\hline
\end{tabular}

* $t$ values greater than 1.96 indicate significant path coefficients on the .05 level for a two-tailed test

Table 4

Beta matrix: structural model

\begin{tabular}{|c|c|c|}
\hline$N=178$ & $\begin{array}{l}\text { TRANSFORMATIONAL } \\
\text { LEADERSHIP }\end{array}$ & TRUST \\
\hline Transformational Leadership & - & $\begin{array}{r}0.609 \\
(0.080) \\
7.589^{*}\end{array}$ \\
\hline Trust & $\begin{array}{r}0.609 \\
(0.080) \\
7.589^{*}\end{array}$ & - \\
\hline Team Commitment & $\begin{array}{r}0.658 \\
(0.413) \\
5.965\end{array}$ & $\begin{array}{r}1.258 \\
(0.250) \\
5.023^{\star}\end{array}$ \\
\hline
\end{tabular}

* $t$ values greater than 1.96 indicate significant path coefficients on the .05 level for a two-tailed test

team-commitment questionnaire (Allen \& Meyer, 1990). Only two of the five dimensions of the SUEIT (Palmer \& Stough, 2002), however, could be replicated and one overall dimension of transformational leadership was obtained from the sample of this study. The MLQ was originally conceptualised with four factors (Bass \& Avolio, 1995). Furthermore, considering CFA results, it was found that these measures fit the data poorly. CFA results did, however, show that the measurement models derived from the EFA fit the data from this sample better than the original measurement models as developed by the various authors, when the "goodness of fit" indices were compared numerically.

The participants seem to understand the items of trust and team commitment in the same way as that of the respondents in the standardisation samples. Possible reasons for the decrease in the number of factors in the SUEIT and MLQ, however, could be that the South African respondents understood and interpreted the items in a different way to that of those in the standardisation samples in the United States of America and Australia, respectively. According to Kerlinger and Lee (2000), differences in sex, education, social and cultural background, or anything else that introduces correlation between variables can create or produce factors. The difference between the factors that emerged in the South African sample of this study and those that emerged in the standardisation samples used by the original authors could be ascribed to the abovementioned differences (in other words, differences in sex, education and social and cultural background). The different ways in which the items loaded on the factors is attributed to the same reasons. A further explanation could be that the qualification level of the respondents may be lower than that of the respondents used in the development of the scales. The SUEIT specifies a minimum of Grade 8 to 9 reading level as applicable to Australian schools (Palmer \& Stough, 2002). The average qualification level of the participants in the obtained sample was between Grade 8 and Grade 12. This may be a lower level of education than the prescribed requirement for the comprehension and completion of the scale. The fact that the questionnaires were drafted in English could also have contributed to a misinterpretation of the questions, since English was the first language of only 20,2\% of the participants. This result should serve to warn researchers sbout the indiscriminate use of measures within the South African organisational context without first establishing their validity and reliability.

This study was an exploratory attempt to investigate a conceptual model consisting of the four constructs. It was developed through the interrogation of the various bivariate relationships that make up this model and that further led to the formulation of six hypotheses. These hypotheses and the structural model were tested with SEM and the structural model was found to fit the data satisfactorily. Furthermore, all six hypotheses, representing the various bivariate relationships among the constructs, were corroborated.

The first hypothesis suggested a positive relationship between transformational leadership and leader emotional intelligence and was accepted based on the significant path estimates that wereobtained.Theresultcorroborated thefindings of Ashkanasy and Tse (1998), Barling et al. (2000), Prati et al. (2003), Riggio and Pirozzolo (2002) and Sosik and Megerian (1999), who all find similar results and conclude that successful transformational leaders also score high on emotional intelligence.

Regarding the role that emotionally intelligent leadership plays in teams, the second hypothesis proposed that a positive relationship exists between team-leader emotional intelligence and trust. This hypothesis was corroborated by and was in line with the findings of Barling et al. (2000), who find that leaders who are able to understand and manage their emotions and display self-control act as role models for their followers, thereby enhancing their followers' level of trust and respect for their leader. Gardner \& Stough (2002) describe this ability to control emotions experienced at work as integral to effective leadership.

Furthermore, the third hypothesis proposed a positive relationship between team-leader emotional intelligence and team commitment. Support for this relationship was obtained, corroborating the findings of Abraham (1999), Humphreys et al. (2005) and Gardner and Stough (2003), who similarly find significant positive correlations between emotional intelligence and organisational commitment.

Bearing in mind the role that transformational leadership plays in teams, the fourth hypothesis proposed a positive relationship between transformational leadership and trust. The findings obtained provided evidence that led to the acceptance of this notion. Similarly, Pillai et al. (1999) and Dirks and Ferrin (2002) report findings that transformational leadership is strongly predictive of trust. Transformational leaders are considered trustworthy, as they use inspirational motivation to be optimistic, enthusiastic and promote attainable goals. Through individualised consideration, they further show interest in the well-being of all subordinates.

Support was also found in this study for the fifth hypothesis, which explored the relationship between transformational leadership and team commitment. The result corroborated the findings of Cheung (2000), Holland (1985) and O'Reilly, Chatman and Caldwell (1991). These authors conclude that effective leadership can increase employees' commitment when their leaders establish a supportive climate that takes care of their well-being, that accepts their opinion, that provides them with encouragement, adequate information and good working conditions and that formulates clear and reasonable goals. Isaksen and Lauer (2002) find that a climate of fairness in teams causes team members to believe that their own interests and those of the team coincide. These are all aspects influenced by transformational leadership.

The final and sixth hypothesis, which is based, in part, on the previous notion, proposed a positive relationship between trust and team commitment. It was believed that the findings 
obtained in this study corroborated this hypothesis and it was accepted on the basis of the significant path estimate that was found. Team transactions characterised by interpersonal trust promote an environment in which individuals feel free to express their ideas, engage in problem solving and resolve differences of opinion (French \& Bell, 1984). Trust, within social and leadership relationships, is positively related to organisational effectiveness, organisational climate and health, performance and achievement (Tschannen-Moran, 2001). Katzenbach and Smith (1993) encourage team leaders in teambased organisations to take the risks necessary to develop and strengthen collective trust, which leads to greater team commitment and enables more effective teamwork.

\section{Limitations and recommendations for future research}

The largest limitations of this study relate to the nature of the sample. The instruments seem to be fairly sophisticated and, even though a pilot study was conducted, it seems that the relatively low level of schooling of the respondents could have influenced the results negatively. Another limitation could be that the questionnaire was not compiled in the mother tongue of most of the respondents. The portability of the instruments could also be identified as a limitation. Future studies should attempt to measure the constructs with different measures and to use a variety of instruments to enable the convergent and discriminant validities to be tested with CFA.

A further limitation is that of mono-method bias or common-method variance. The problem derives from the fact that the source of the data for the predictors was not separated from the source of their outcomes. All the latent variables were measured from a single source (in other words, the team member) at a given time. Any relationship that existed could therefore be attributed to a response bias on the part of the respondent.

Another limitation is that, even though causal conceptual arguments are made regarding the relationships among the constructs, the cross-sectional nature of the research design does not allow for causal inferences to be made. Future studies should attempt to address this.

\section{Managerial implications of the findings}

This study showed that organisations should recruit, select and develop their team leaders with great care. Effective leadership behaviours, such as those demonstrated by transformational and emotionally intelligent leaders, seem to be related to higher levels of commitment and trust in team members, which, consequently, have the potential to impact positively on the performance of the team and even the performance of the organisation. Adequate training and development should be provided for leaders who score low on emotional intelligence and transformational-leadership behaviour.

\section{Conclusion}

Thisstudy was an exploratory attempt to test an integrated model consisting of transformational leadership, leader emotional intelligence, trust and team commitment. In particular, the objective of the study was to investigate these different implied theoretical relationships within a team context. As far as could be established, such an integrated model had not been tested in this context before. The study makes a valuable contribution in theory building and practice in the field of organisational psychology, especially in the South African context, as it goes beyond the testing of the bivariate relationships among the constructs. The use of SEM allows for the testing of a more complex model that takes into account interaction effects among the constructs that other statistical techniques cannot do. Investigation of the various relationships among the constructs as they work together provides a more realistic account of the complexity found in the "real world".
The results of this study make several contributions to research literature. The first is the finding that the original measurement models or configurations in some cases could not be replicated in this sample and differed from those proposed by the author/ $\mathrm{s}$ who developed them. This should, at the least, serve as some warning to researchers who arbitrarily use scales developed elsewhere when conducting research within South Africa. It cannot be presumed that factorial configuration will be the same across continents and cultures. It would therefore be prudent to establish validity and reliability before inferences are drawn on the basis of measures obtained. Care should further be taken to assess respondents' comprehension of items to ensure that language is not a complicating factor.

Using SEM, the study confirmed the conceptual model as well as all the hypothesised relationships among the constructs within a team context. Transformational leadership behaviour was found to be positively related to team-leader emotional intelligence and both these constructs were found to be positively related to trust (both in the team leader and in team members) and to team commitment. The results strengthen and underline the importance of effective leadership within effective teams. It seems that leaders are important creators and sustainers of the processes and dynamics responsible for effective teams.

\section{REFERENCES}

Abraham, R. (1999). Emotional intelligence in organizations: A conceptualization. Genetic, Social and General Psychology Monographs, 125(2), 209-222.

Allen, N.J. \& Meyer, J.P. (1990). The measurement and antecedents of affective, continuance and normative commitment to the organisation. Journal of Occupational Psychology, 63(2), 1-18.

Ashforth, B. \& Humphrey, R. (1995). Emotion in the workplace: A reappraisal. Human Relations, 48(2), 97-124.

Ashkanasy, N. \& Tse, B. (1998). Transformational leadership as management of emotion: A conceptual review. Paper presented at the First International Conference on Emotions and Organisational Life, San Diego, CA.

Barling, J., Slater, F. \& Kelloway, E.K. (2000). Transformational leadership and emotional intelligence: An exploratory study. Leadership and Organizational Development Journal, 21, 157-161.

Bass, B. (1997). Does the transactional-transformational leadership paradigm transcend organizational and national boundaries? American Psychologist, 52, 130-139.

Bass, B.M. (1985). Leadership and performance beyond expectations. New York: Free Press.

Bass, B.M. \& Avolio, B.J. (1994). Improving organizational effectiveness through transformational leadership. London: Sage Publications.

Bass, B.M. \& Avolio, B.J. (1995). Multifactor leadership questionnaire report. Palo Alto: Mind Green.

Becker, T.E. (1992). Foci and bases of commitment: Are they distinctions worth making? Academy of Management Journal, 35(1), 232-244.

Becker, T.E. \& Billings, R.S. (1993). Profiles of commitment: An empirical test. Journal of Organisational Behaviour, 14, 177190.

Biloslavo, R. (2004). The systems thinking approach to development of the knowledge management framework. International Journal of Learning and Intellectual Capital, 1(2), 201-224.

Bishop, J.W. \& Scott, K.D. (1996). Multiple foci of commitment in a work team environment. Academy of Management Proceedings, 269-273.

Bishop, J.W. \& Scott, K.D. (1997). Employee commitment and work team productivity. HR Magazine, 11, 107-111.

Bishop, J.W., Scott, K.D. \& Casino, L.S. (1997). The differential effects of team commitment and organisational commitment on job performance and intention to quit. Paper presented 
at the Annual Meeting of the Academy of Management, Boston.

Bollen, K.A. \& Long, J.S. (1993). Testing structural equations. Newbury Park, CA: Sage Publications.

Brief, A.P. \& Aldag, R.J. (1980). Antecedents of organisational commitment among hospital nurses. Sociology of Work and Occupations, 7(2), 210-221.

Burns, J.M. (1978). Leadership. New York: Harper and Row.

Carlos, G. \& Taborda, M. (2000). Leadership, teamwork and empowerment: Future management trends. Cost Engineering, 42(10), 41-44.

Carnevale, D.G. \& Weschler, B. (1992). Trust in the public sector: Individual and organizational determinants. Administration and Society, 23(4), 471-494.

Cheung, C. (2000). Commitment to the organisation in exchange for support from the organisation. Social Behaviour and Personality, 28(2), 125-140.

Chuang, Y.T., Church, R. \& Zikic, J. (2004). Organizational culture, group diversity and intra-group conflict. Team Performance Management, 10(1/2), 26-34.

Colquitt, J.A. (2002). Justice in teams: Antecedents and consequences of procedural justice climate. Personnel Psychology, 55(1), 83-110.

Conger, J.A., Kanungo, R.N. \& Menon, S.T. (2000). Charismatic leadership and follower effects. Journal of Organizational Behavior, 21(7), 747-767.

Cunningham, J.B. \& MacGregor, J. (2000). Trust and the design of work: Complementary constructs in satisfaction and performance. Human Relations, 53(12), 1575-1591.

Davies, M., Stankov, L. \& Roberts, R.D. (1998). Emotional intelligence: In search of an elusive construct. Journal of Personality and Social Psychology, 75, 989-1015.

DeCottiis, T.A. \& Summers, T.P. (1987). A path analysis of a model of the antecedents and consequences of organisational commitment. Human Relations, 40(7), 445-470.

Dew, J., (1995), Creating Team Leaders, The Journal for Quality and Participation, 18(6), 50-54

Diamantopoulos, A. \& Siguaw, J. (2000). Introducing Lisrel. London: Sage Publications.

Dirks, K. (2000). Trust in leadership and performance: Evidence from NCAA basketball. Journal of Applied Psychology, 85, 1004-1012.

Dirks, K.T. \& Ferrin, D.L. (2002). Trust in leadership: Metaanalytic findings and implications for research and practice. Journal of Applied Psychology, 87, 611-628.

Duarte, D.L. \& Snyder, N.T. (1999). Mastering virtual teams. San Francisco: Jossey-Bass.

Erdem, F. (2003). Optimal trust and teamwork: from groupthink to team think. Work Study, 52(5), 229-223.

Fabrigar, L.R., Wegener, D.T., MacCallum, R.C. \& Strahan, E.J. (1999). Evaluating the use of exploratory factor analysis in psychological research. Psychological Methods, 4, 272-299.

Ferres, N., Connell, J. \& Travaglione, A. (2004). Co-worker trust as a social catalyst for constructive employee attitudes. Journal of Managerial Psychology, 19(6), 608-622.

Ferres, N. \& Travaglione, T. (2003). The development and validation of the workplace trust survey (WTS): Combining qualitative and quantitative methodologies. Paper presented at the APROS, Mexico.

Feyerherm, A.E. \& Rice, C.L. (2002). Emotional intelligence and team performance: The good, the bad and the ugly. The International Journal of Organisational Analysis, 10(4), 343362.

Fisher, K. (1993). Leading self-directed work teams: A guide to developing new team leadership skills. New York: McGrawHill.

Flood, P.C., Hannan, E., Smith, K.G., Turner, T., West, M.A \& Dawson, J. (2000). Chief executive leadership style, consensus decision-making and top management team effectiveness. European Journal of Work and Organisational Psychology, 9(3), 401-420.
Franken, A. \& Braganza, A. (2006). Organisational forms and knowledge management: One size fits all? International Journal of Knowledge Management Studies, 1(1/2), 18-37.

French, W. \& Bell, C. (1984). Organizational development: Behavioral science interventions for organizational movement. Englewood Cliffs, NJ: Prentice Hall.

Gallie, D. \& White, M. (1993). Employee commitment and the skills revolution. First findings from the Employment in Britain Survey, Policy Studies Institute, London.

Gardner, L. \& Stough, C. (2002). Examining the relationship between leadership and emotional intelligence in senior level managers. Leadership and Organizational Development Journal, 23(2), 68-78.

Gardner, L. \& Stough, C. (2003). Assessing the relationship between workplace emotional intelligence, job satisfaction and organisational commitment. Australian Journal of Psychology, 55 (Supplement).

George, J.M. (2000). Emotions and leadership: The role of emotional intelligence. Human Relations, 53(8), 1027-1044.

Goleman, D. (1995). Emotional intelligence: Why it can matter more than IQ. New York: Bantam.

Goleman, D. (1998). Working with emotional intelligence. New York: Bantam.

Goleman, D., Boyatzis, R. \& McKee, A. (2002). Primal leadership: Realizing the power of emotional intelligence. Boston, MA Harvard Business School Press.

Gomez, C. \& Rosen, B. (2001). The leader-member exchange as a link between managerial trust and employee empowerment. Group and Organizational Management, 26, 53-70.

Gorsuch, R.L. (1997). Exploratory factor analysis: Its role in item analysis. Journal of Personality Assessment, 68, 532-560.

Gregersen, H.B. (1993). Multiple commitments at work and extra role behaviour during three stages of organizational tenure. Journal of Business Research, 26, 31-47.

Harris, T.E. (1992). Toward effective employee involvement: An analysis of parallel and self-managing teams. Journal of Allied Business Research, 9(1), 25-33.

Hartog, D.N.D. \& Van Muijen, J.J. (1997). Transactional versus transformational leadership: An analysis of the MLQ. Journal of Occupational \& Organisational Psychology, 70(1), 19-35.

Heise, D.R. (1989). Effects of emotion displays on social identification. Social Psychology Quarterly, 52(1), 10-21.

Holland, J.L. (1985). Making vocational choices: A theory of vocational personalities and work Environments. Englewood Cliffs, NJ: Prentice-Hall.

Humphreys, J., Brunsen, B. \& Davis, D. (2005). Emotional structure and commitment: Implications for health care management. Journal of Health Organisation and Management, 19(2), 120-129.

Huusko, L. (2006). The lack of skills: An obstacle in teamwork Team Performance Management, 12(1/2), 5-16.

Isaksen, S.G. \& Lauer, K.J. (2002). The climate for creating and change in teams. Creativity and Innovation Management, $11(1), 74-86$

Katzenbach, J.R. (1998). The work of teams. Boston, MA: Harvard Business School Press.

Katzenbach, J.R. (2000). Peak performance: Aligning the hearts and minds of your employees. Boston, MA: Harvard Business School Press.

Katzenbach, J.R. \& Smith, D.K. (1993). The wisdom of teams. Boston, MA: Harvard Business School Press.

Katzenbach, J.R. \& Smith, D.K. (1994). The wisdom of teams: Creating the high performance organisation. Boston, MA: Harvard Business School Press.

Kelloway, E.K. (1998). Using Lisrel for structural equation modeling. Thousand Oaks: Sage Publications.

Kerlinger, F.N. \& Lee, H.B. (2000). Foundations of behavioral research (4th ed.). New York: Holt, Rinehart and Winston.

Knutson, K.A. \& Miranda, A.O. (2000). Leadership characteristics, social interest, and learning organizations. Journal of Individual Psychology, 56(2), 205-213. 
Konovsky, M.A. \& Pugh, S.D. (1994). Citizenship behavior and social exchange. Academy of Management Journal, 37(3), 656669.

Kratzer, J., Leenders, R.T.A.J. \& Engelen, J.M.L. (2004). A delicate managerial challenge: How cooperation and integration affect the performance of teams. Team Performance Management, 10(1/2), 20-25.

Kreitner, R. \& Kinicki, A. (2007). Organisational behaviour (7th ed.). Chicago: Irwin.

Larson, C.E. \& La Fasto, F.M. (1989). Teamwork: What must go right, what can go wrong. Newbury Park, CA: Sage Publications.

Law, K.M.Y. \& Chuah, K.B. (2004). Project-based action learning as learning approach in learning organisation: The theory and framework. Team Performance Management, 10(7/8), 178186

Lawler, E.E., III, Mohrman, S.A., \& Ledford, G.E., Jr. (1995). Creating high performance organizations: Practices and results of employee involvement and total quality management in Fortune 1000 companies. San Francisco: Jossey-Bass.

Lewis, B.J. (1999). Effective team leadership. Journal of Management in Engineering, 15(3), 7.

Lewis, K.M. (2000). When leaders display emotion: How followers respond to negative emotional expression of male and female leaders. Journal of Organisational Behaviour, 21, 221-234.

Lowe, K.B., Kroeck, K.G. \& Sivasubramaniam, N. (1996). Effectiveness correlates with transformational and transactional leadership: A meta-analytic review. Leadership Quarterly, 7, 385-425.

Mathieu, J.E. \& Zajac, D.M. (1990). A review and meta-analysis of the antecedents, correlates, and consequences of organisational commitment. Psychological Bulletin, 108(2), 171-194.

Mayer, J.D. \& Salovey, P. (1995). Emotional intelligence and the construction and regulation of feelings. Applied and Preventive Psychology, 4, 197-208.

Mayer, J.D. \& Salovey, P. (1997). What is emotional intelligence? In P. Salovey \& D. Sluyter (eds.), Emotional development and emotional intelligence. New York: Basic Books.

Mishra, A. \& Morrisey, M.A. (1990). Trust in employee/employer relationships: A survey of West Michigan managers. Public Personnel Management, 19(4), 443-461.

Morgan, R. \& Hunt, S. (1994). The commitment-trust theory of relationship marketing. Journal of Marketing, 58(3), 20-38.

Natale, S.M., Sora, S.A. \& Kavalipurapu, S.B. (2004). Leadership in teams: Managerial responses. Team Performance Management, 10(3/4), 45-52.

Nijhof, W.J., De Jong, M.J. \& Beukhof, G. (1998). Employee commitment in changing organisations: An exploration. Journal of European Industrial Training, 22(6), 243-248.

O'Reilly, C.A., Chatman, J. \& Caldwell, D.F. (1991). People and organisational culture: A profile comparison approach to assessing person-organisation fit. Academy of Management Journal, 34, 487-516.

Palmer, B. \& Stough, C. (2002). Workplace SUEIT interim technical manual. Version 2. Swinburne University of Technology.

Parker, S. \& Wall, T. (1998). Job and work design: Organising work to promote well-being and effectiveness. London: Sage Publications.

Pillai, R., Schriesheim, C.A. \& Williams, E.A. (1999). Fairness perceptions and trust as mediators for transformational and transactional leadership: A two-sample study. Journal of Management, 25(6), 161-192.
Podsakoff, P.M., MacKenzie, S.B., Moorman, R.H. \& Fetter, R. (1990). Transformational leader behaviors and their effects on followers' trust in the leader, satisfaction and organizational citizenship behaviors. Leadership Quarterly, 1(2), 107-142

Prati, L.M., Douglas, C., Ferris, G.R., Ammeter, A.P. \& Buckley, M.R. (2003). Emotional intelligence, leadership effectiveness and team outcomes. The International Journal of Organisational Analysis, 11(1), 21-40.

Procter, S. \& Mueller, F. (2000). Teamworking. London: MacMillan.

Rabey, G. (2003). The paradox of teamwork. Industrial and Commercial Training, 35(4), 158-162.

Rich, G.A. (1997). The sales manager as a role model: Effects of trust, job satisfaction and performance of salespeople. Journal of the Academy of Marketing Science, 25, 319-328.

Riggio, R.E. \& Pirozzolo, F.J. (2002). Multiple intelligences and leadership: Implications for leadership. In R.E. Riggio \& S.E. Murphy (eds.), Multiple intelligences and leadership. Mahwah, NJ: Lawrence Erlbaum Associates.

Robbins, S. (2003). Essentials of organisational behaviour (7th ed.). Englewood Cliffs, NJ: Prentice Hall.

Roodt, G. (1997). Theoretical and empirical linkages between work-related commitment foci. Journal of Industrial Psychology, 23(2), 6-13.

Rousseau, S.B., Sitkin, S.B., Burt, R.S. \& Camerer, C. (1998). Not so different after all: A cross-discipline view of trust. Academy of Management Review, July, 393-404.

Salovey, P. \& Mayer, J.D. (1990). Emotional intelligence. Imagination, Cognition and Personality, 9(3), 185-211.

Scott, K.D. \& Townsend, A.M. (1994). Teams: Why some perform and others do not. HR Magazine, 39(12), 62-67.

Shore, L.M. \& Wayne, S.J. (1993). Commitment and employee behaviour: Comparison of affective commitment and continuance commitment with perceived organizational support. Journal of Applied Psychology, 79(5), 774-780.

Sosik, J.J. \& Megerian, L.E. (1999). Understanding leader emotional intelligence and performance: The role of selfother agreement on transformational leadership perceptions. Group and Organisation Management, 32(3), 340-366.

Steyrer, J. (1998). Charisma and the archetypes of leadership. Organization Studies, 19(5), 807-827.

Tan, H.H. \& Tan, C. (2000). Toward the differentiation of trust in supervisor and trust in organization. Genetic, Social and General Psychology Monographs, (126), 241-260.

Tschannen-Moran, M. (2001). Collaboration and the need for trust. Journal of Educational Administration, 39(4), 308-331.

West, M.A., Tjosvold, D. \& Smith, K.G. (2003). International handbook of organizational teamwork and cooperative working. New York, NY: Wiley.

Williams, T. (1998). Job satisfaction in teams. The International Journal of Human Resource Management, 9 (5),782-799

Wilson, J.M., George, J. \& Wellins, R.S. (1994). Leadership trapeze: Strategies for leadership in team-based organisations. San Francisco, CA: Jossey-Bass.

Wong, C.S. \& Law, K.S. (2002). The effects of leader and follower emotional intelligence on performance and attitude: An exploratory study. The Leadership Quarterly (13), 243-274.

Woodcock, M. \& Francis, D. (1994). Teambuilding strategy. Hampshire: Gower Publishing.

Yukl, G. (2002). Leadership in Organisations (5th ed.). New Jersey: Prentice-Hall. 